\title{
Rotor Loads Reduction by Dynamically Extendable Chord
}

\author{
Dong $\operatorname{Han}^{1}$ \\ Nanjing University of Aeronautics and Astronautics, Nanjing, Jiangsu, 210016, China \\ and \\ George N. Barakos ${ }^{2}$ \\ University of Glasgow, Glasgow, Scotland G12 8QQ, United Kingdom
}

\begin{abstract}
Dynamically extendable blade chord sections show promise for reducing helicopter rotor loads. A rotor model based on elastic beam concept, and capable to predict helicopter power, is utilized. A stiff in-plane four bladed rotor with the shape similar to the UH-60A rotor, is used as baseline for comparisons. For the control of the $4 /$ rev vertical hub force, it is not beneficial to actuate the extendable chord at hover and low speed flight. At a high speed of $270 \mathrm{~km} / \mathrm{h}$, the extendable chord, with a width of $10 \%$ rotor radius and responded to an extension of $10 \%$ chord length, obtained a maximum force reduction of $89.4 \%$. The magnitude of the dynamic chord needs to be optimized according to the flight state. The performance can be enhanced by increasing the extension or width of the dynamic chord. The dynamically extendable chord was not suitable for reducing the $2 /$ rev blade flapwise root bending moment. A 3/rev dynamic chord extension though showed great potential in reducing the $3 /$ rev flapwise root bending moment and the $4 /$ rev rotor rolling and pitching moments, simultaneously. The effectiveness of a 5/rev dynamic chord in reducing the 4/rev rotor rolling or pitching moment degraded significantly compared with a $3 /$ rev actuation.
\end{abstract}

\footnotetext{
${ }^{1}$ Professor, College of Aerospace Engineering; donghan@nuaa.edu.cn (Corresponding Author).

${ }^{2}$ Professor, CFD Laboratory, School of Engineering; George.Barakos@glasgow.ac.uk.
} 


\section{Nomenclature}

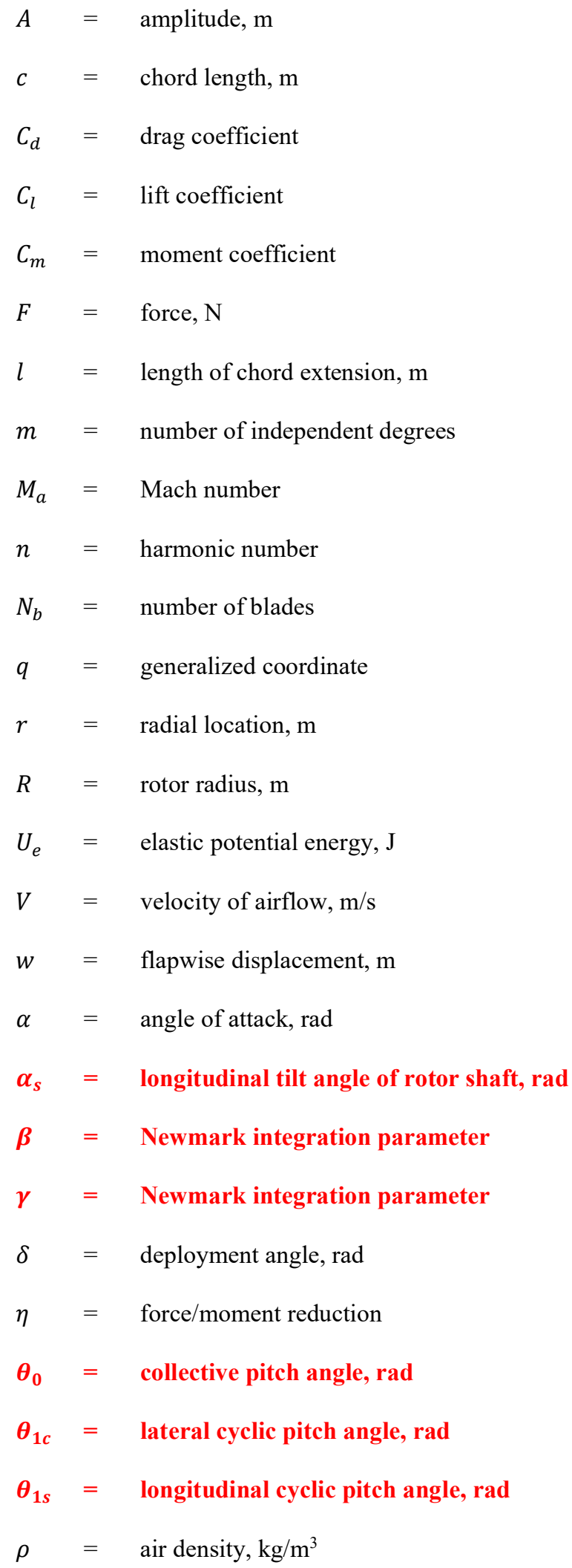




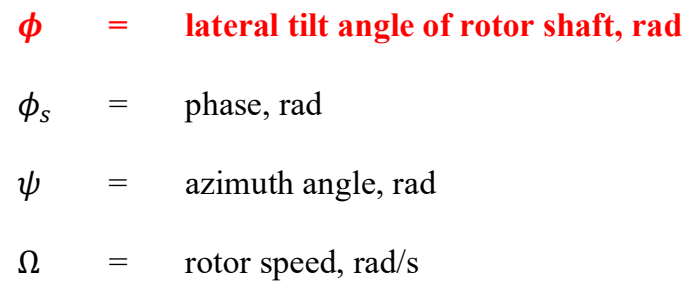

\section{I.Introduction}

Helicopters have a reputation for low ride quality due to high vibration and noise levels, primarily caused by the complex aerodynamic environment of the main rotor. To reduce fuselage vibration caused by the main rotor, three methods are used, (1) reduction of the vibratory loads generated by the main rotor, (2) isolation of the loads in the middle of the transfer path from the main rotor to the fuselage, (3) control of the high vibration at the fuselage using active or passive devices. Directly reducing the rotor loads can reduce the components undergoing the high vibratory input from the rotor, and this approach has so far received the interest of many researchers [1-5].

Several passive and active vibration control methods in controlling the blade or hub loads of helicopter rotors have so far been reported, such as the dynamic vibration absorber [1, 2], higher harmonic control [2-4], individual blade pitch control $[3,4]$, actively controlled trailing edge flaps [3-5], active twist rotor $[4,5]$, active composite box beam [6], deployable Gurney flaps [5, 7], embedded flapwise absorbers [8], and so on. For the control of the rotor loads in the same direction as the rotor thrust, an intuitive concept is that a portion of the thrust generated by the blades can be controlled to generate a harmonic force or moment to cancel the target load. One possible method is to change the chord length of some blade section.

Léon et al. investigated quasi-statically extendable chord sections to expand the envelope of the UH-60 helicopter [9], and the investigations showed promise. The analyses of extendable chord rotors for flight performance improvement by Khoshlahjeh and Gandhi indicated significant power reduction at high gross weight and altitude, and performance improvements at maximum speed, gross weight and altitude [10]. Kang et al. pointed out that the extendable blade chord had significant potential in reducing the rotor power, especially at high speed flight [11]. Han et al. explored the potential of the static (0/rev) and dynamic (1-4/rev) extendable chord in reducing the rotor power and improving flight performance [12]. Generally, a lower harmonic extendable chord could save more rotor power than one actuated at higher harmonics, and the dynamic chord could reduce the power further than the corresponding static chord extension. Past research, concentrated on the potential of statically and 
Dynamically Extendable Chord (DEC) in improving the performance of helicopters. The question whether this concept has potential in reducing the vibratory loads of helicopter rotors is the topic of this paper.

As we all know, the non-uniform airflow passing through a rotor can excite oscillating airloads on the blades, which produce excitation forces and moments at the rotor hub. The rotor acts like a filter. For an ideal rotor with identical blades [1], the major excitations from the blades at the frequencies of $\left(N_{b}-1\right) \Omega, N_{b} \Omega,\left(N_{b}+1\right) \Omega,\left(2 N_{b}-1\right) \Omega$, $2 N_{b} \Omega,\left(2 N_{b}+1\right) \Omega, \cdots$, can be transmitted to the fixed frame (rotor hub, fuselage) at the frequencies of $N_{b} \Omega, 2 N_{b} \Omega$, ... The dynamically extendable chord can generate vertical blade root forces and blade flapwise root bending moments at the frequencies of $\Omega, 2 \Omega 3 \Omega, \cdots$, which can be applied to control the vertical hub forces and rotor rolling and pitching moments at the frequencies of $N_{b} \Omega, 2 N_{b} \Omega, \cdots$. For a four bladed rotor, the $4 / \mathrm{rev}$ DEC can therefore be used to reduce the $4 / \mathrm{rev}$ vertical hub force, and the $3 / \mathrm{rev}$ and $5 / \mathrm{rev}$ can be used to reduce the $4 / \mathrm{rev}$ rotor rolling and pitching moments. The present work focuses on the potential of dynamically extendable chord in controlling the loads of helicopter rotors. A helicopter model, which has already been used to analyze the improved helicopter rotor performance by the extendable chord [12], is used. Parametric analyses are conducted to enhance the potential of chord extension in reducing the loads.

\section{II.Modeling Method}

\section{A. Rotor Loads}

To evaluate the potential of the dynamically extendable chord in controlling the rotor loads, an aeroelastic model is used, consisting of a main rotor, fuselage, tail rotor and a propulsive trim method. The rotor model follows [13, 14], adopting a beam structural model, an airfoil aerodynamic model and an rotor induced velocity model. The employed elastic beam model allows for moderate deflections, and captures the nonlinear coupling effects between deformations of advanced helicopter blades. The rigid rotations associated with the blade hinges and the blade rotation about the rotor shaft are introduced as generalized coordinates. Look-up airfoil aerodynamics is used. The induced velocity over the rotor disk is captured by the Pitt-Peters inflow model [15]. Assembling the structural, kinetic, and aerodynamic terms yields the equations of motion based on the generalized force formulation [13]. The Newmark integration method without numerical dissipation $\left(\gamma=0.5\right.$, and $\left.\beta=(\gamma+0.5)^{2} / 4\right)$ is utilized to calculate the steady responses in the time domain [16]. The fuselage is treated as a rigid body with aerodynamic 
forces and moments. The thrust of the tail rotor is determined by the main rotor torque divided by the distance from the hub center of the tail rotor to the main rotor shaft.

Given three initial pitch controls (collective and cyclic angles) and two rotor shaft attitude angles (longitudinal and lateral tilt shaft angles), the periodic response of the rotor can be obtained for a prescribed forward speed. The hub forces and moments of the main rotor are balanced by the forces and moments acting on the fuselage and tail rotor. The forces and moments on the fuselage are determined by the flight state and attitude angles. The thrust and power of the tail rotor is derived from the rotor torque and flight state. These component forces and moments constitute the equilibrium equations of the helicopter, which are solved to update the pitch controls and rotor attitude angles for the next iteration. In the trim, the convergence state is defined as $\sqrt{\left[\left(\Delta \boldsymbol{\theta}_{0}\right)^{2}+\left(\Delta \boldsymbol{\theta}_{1 c}\right)^{2}+\left(\Delta \boldsymbol{\theta}_{1 s}\right)^{2}+\left(\Delta \boldsymbol{\alpha}_{s}\right)^{2}+\left(\Delta \boldsymbol{\phi}_{s}\right)^{2}\right] / 5}<1.0 \times 10^{-5}$. The symbol ' $\Delta$ ' means the difference between two adjacent integration steps. After iterations of the periodic rotor responses, and solution of the equilibrium equations, the converged or trimmed pitch controls and rotor attitude angles can be obtained. Then the main rotor power and related information of the helicopter can be derived.

The hub forces and moments of the main rotor are derived from the resultant root forces and moments of the blades. Because the externally applied forces (including the centrifugal force and inertial force), are reacted by the structure, the root forces and moments are calculated using the generalized structural forces corresponding to the degrees of freedom. For example, the variation of the elastic potential energy can be expressed as

$$
\delta U_{e}=\sum_{i=1}^{m} F_{i} \delta q_{i}
$$

where, $F_{i}$ is a generalized elastic force, and $q_{i}$ is a generalized elastic degree of freedom. If the structural root force in the vertical direction is desired, the force is the generalized nodal force $F_{w}$ corresponding to the flapwise displacement degree $w$ at the blade root. Because of the pitch controls, a transformation needs to be conducted to transfer the forces and moments from the blade rotating frame to the hub fixed frame. The required harmonic components of the forces or moments can be calculated by integrating the time histories of the response, i.e., 


$$
\left\{\begin{array}{c}
\left(F_{i}\right)_{0}=\frac{1}{2 \pi} \int_{0}^{2 \pi} F_{i}(\psi) d \psi \\
\left(F_{i}\right)_{n c}=\frac{1}{\pi} \int_{0}^{2 \pi} F_{i}(\psi) \cos (n \psi) d \psi \\
\left(F_{i}\right)_{n s}=\frac{1}{\pi} \int_{0}^{2 \pi} F_{i}(\psi) \sin (n \psi) d \psi
\end{array}\right.
$$

where, $c$ denotes the cosine component, and $s$ denotes the sinusoidal component.

\section{B. Extendable Chord}

An extendable chord can change the chord and airfoil camber according to a deployment schedule, as shown in Figure 1, and thus modifies the aerodynamic characteristics of the baseline airfoil. The classic thin airfoil theory gives an explicit expression of the lift coefficient of the symmetrical airfoil of NACA 0012 with an extended trailing edge [17], i.e. extendable chord, as

$$
\bar{C}_{l}=2 \pi(1+\varepsilon)\left[\alpha+\tan \delta\left(1-\frac{\theta_{c}}{\pi}+\frac{\sin \theta_{c}}{\pi}\right)\right]
$$

where,

$$
\begin{gathered}
\theta_{c}=\cos ^{-1}[(\varepsilon-1) /(\varepsilon+1)] \\
\varepsilon=l \cos \delta / c
\end{gathered}
$$

where, $\varepsilon$ represents the chord extension as a percentage of the baseline chord length $c$. With a deployment angle of $0^{\circ}, \bar{C}_{l}$ is proportional to $\varepsilon$. For the SC1094R8 cambered airfoil, the CFD method predicts the deployment angle to be $2^{\circ}[10]$. It is obvious that, with a suitable deployment angle, the aerodynamic characteristics of the airfoil with a chord extension can remain almost the same. 


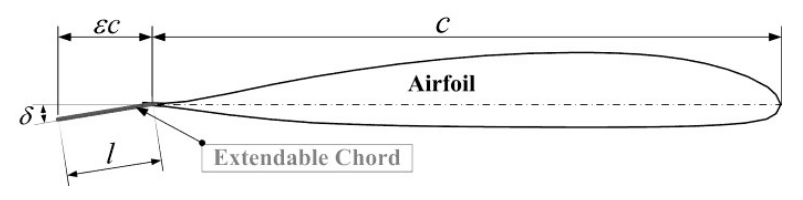

Figure 1: Configuration of extendable Chord.

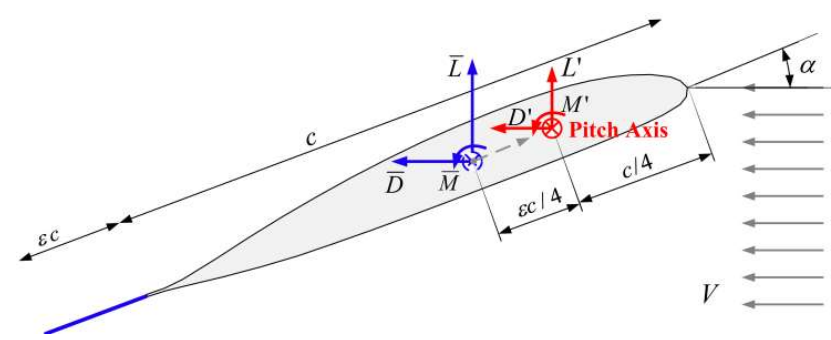

Figure 2: The resultant forces and moment at the pitch axis.

In this work, we assume that the chord extension does not change the aerodynamic characteristics of the airfoils.

$\overline{()}$ denotes variables related to the airfoil with a chord extension. The lift, drag and moment coefficients $\bar{C}_{l}, \bar{C}_{d}$ and $\bar{C}_{m}$ for an airfoil with an extendable chord are related with the baseline coefficients $C_{l}, C_{d}$ and $C_{m}$ as [10]

$$
\left\{\begin{array}{c}
\bar{C}_{l}=(1+\varepsilon) C_{l} \\
\bar{C}_{d}=(1+\varepsilon) C_{d} \\
\bar{C}_{m}=(1+\varepsilon)^{2} C_{m}
\end{array}\right.
$$

The effect of the chord extension is equivalent to an increase in the aerodynamic coefficients. Since the pitch axis of the blade locates at the 1/4 chord point of the baseline airfoil, as shown in Figure 2, the pitching moment acting on this point with the chord extension is

$$
M^{\prime}=\bar{M}-\bar{L} \frac{\varepsilon C}{4} \cos \alpha-\bar{D} \frac{\varepsilon C}{4} \sin \alpha
$$

The coefficients at the $1 / 4$ chord point of the baseline airfoil for the airfoil segment $d r$ with a chord extension are 


$$
\left\{\begin{array}{c}
L^{\prime}=\frac{1}{2} \rho V^{2} c(1+\varepsilon) C_{l} d r \\
D^{\prime}=\frac{1}{2} \rho V^{2} c(1+\varepsilon) C_{d} d r \\
M^{\prime}=\frac{1}{2} \rho V^{2} c^{2}\left[(1+\varepsilon)^{2} C_{m}-\frac{(1+\varepsilon) \varepsilon \cos \alpha}{4} C_{l}-\frac{(1+\varepsilon) \varepsilon \sin \alpha}{4} C_{d}\right] d r
\end{array}\right.
$$

Look-up aerofoil aerodynamics is used to calculate the coefficients of $C_{l}\left(\alpha, M_{a}\right), C_{d}\left(\alpha, M_{a}\right)$ and $C_{m}\left(\alpha, M_{a}\right)$, which are functions of angle of attack $\alpha$ and Mach number $M_{a}$.

\section{III.Aeroelastic Analysis}

This work focuses on the control of blade loads in the vertical or flapwise direction, and the corresponding harmonics transferred to the rotor hub. The DEC is explored to reduce harmonic blade and hub loads.

\section{A. Baseline Rotor}

A stiff in-plane four bladed rotor is used as the baseline rotor in the following analysis, which has the same aerodynamic shape as the UH-60A helicopter rotor [18-20]. The rotor blades have uniform distribution of structural properties. The parameters of the rotor system are listed in Table 1. The fundamental flapwise, lagwise and torsional frequencies at the nominal rotor speed are $1.15 / \mathrm{rev}, 1.49 / \mathrm{rev}$ and $7.57 / \mathrm{rev}$, respectively. The baseline flight state is for sea level and take-off weight of $9474.7 \mathrm{~kg}$ (corresponding weight coefficient 0.0074 ).

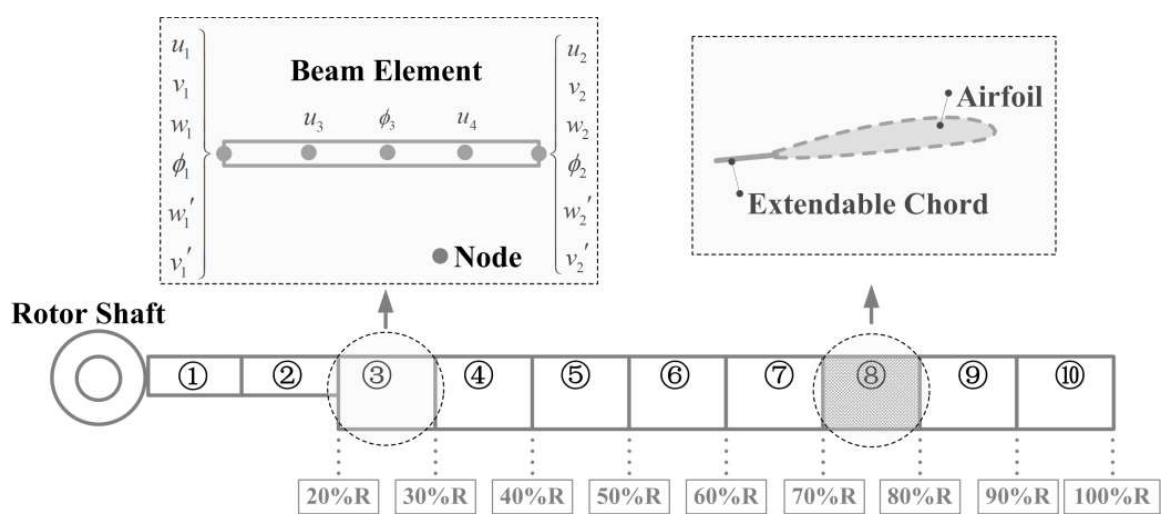

Figure 3: Configuration of extendable chord. 
Table 1: Main rotor parameters.

\begin{tabular}{ll}
\hline \hline Parameter & Value \\
\hline Main Rotor Radius & $8.18 \mathrm{~m}$ \\
Main Rotor Speed $(100 \%)$ & $27.0 \mathrm{rad} / \mathrm{s}$ \\
Blade Chord Length & $0.527 \mathrm{~m}$ \\
Blade Twist & Nonlinear \\
Blade Airfoil & $\mathrm{SC} 1095 / \mathrm{SC} 1094 \mathrm{R} 8$ \\
Number of Blades & 4 \\
Blade Mass per Unit Length & $13.9 \mathrm{~kg} / \mathrm{m}$ \\
Longitudinal Shaft Tilt & $3^{\circ}$ \\
\hline \hline
\end{tabular}

In the following analyses, the extendable chords with $10 \% \mathrm{R}$ as the width are investigated, as shown in Figure 3. The start points of the locations are $20.0 \% \mathrm{R}, 30.0 \% \mathrm{R}, \ldots$, and $90.0 \% \mathrm{R}$ (Locations $3,4, \ldots$, and 10 ), respectively. The length of the extendable chord varies by a prescribed harmonic motion

$$
\varepsilon=A[1.0+\sin (n \Omega t+\phi)]
$$

To determine the best performance of the DEC, a parameter sweep with $15^{\circ}$ increments of the input phase at a prescribed forward flight speed is conducted.

A force or moment reduction ratio is defined to determine the benefits in loads control as:

$$
\eta=\left(1-F / F_{b}\right) \times 100 \%
$$

where, $F$ is the force or moment with the extendable chord and $F_{b}$ is the baseline force or moment to be reduced without any extendable chord.

\section{B. 4/rev Vertical Hub Force}




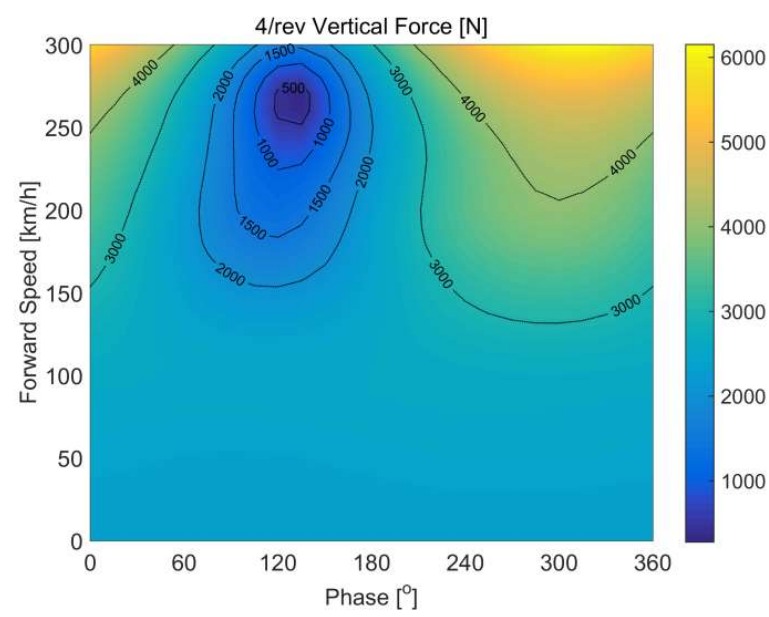

Figure 4: The 4/rev vertical force for different forward speed and input phase $\left(C_{W}=0.0074\right)$.

To reduce the 4/rev vertical hub force, the DEC is tuned to $4 /$ rev. Figure 4 shows the $4 /$ rev vertical hub force with the forward speed and the phase of the DEC. The DEC is deployed at Location 6 (see Figure 3) and the magnitude of the DEC is $10 \% \mathrm{c}$. At hover and low speed flight, the $4 /$ rev force increases significantly compared with the baseline force, but the changes remain substantially small with increasing phase. At these speeds, the DEC increases the load, and it is not necessary to actuate the DEC. At medium to high forward speeds, the $4 / \mathrm{rev}$ force changes significantly with the phase. At a speed of $270 \mathrm{~km} / \mathrm{h}$ and phase of $135^{\circ}$, a minimum of the $4 / \mathrm{rev}$ force appears. It is obvious that the DEC works well, and it can be used to control the 4/rev vertical hub force. With increasing speed, the large variation of the force with the phase remains. It can thus be inferred that the maximum force reduction can be obtained at high-speed flight, which is named as critical speed. If the forward speed is larger than this speed, the force reduction decreases.

Figure 5 compares the $4 / \mathrm{rev}$ vertical hub forces and the corresponding reductions with the baseline for the deployed phases of $120^{\circ}, 135^{\circ}$ and $150^{\circ}$, respectively. The DEC is deployed at Location 6 . The baseline force increases with the forward speed, and is rather small at low speeds. The DEC generates excessive force to counteract the baseline force at hover and low speed flight, which leads to an increase in the resultant $4 /$ rev force. It is natural that the force reduction is negative in the figure, and changes to a positive value at a speed larger than $210 \mathrm{~km} / \mathrm{h}$. At a critical speed (corresponding to the maximum reduction) of $270 \mathrm{~km} / \mathrm{h}$ and phase of $135^{\circ}$, the maximum reduction of $89.4 \%$ can be obtained, and then it decreases with the speed. At high speeds, the force reduction decreases, and it changes to $59.5 \%$ at a speed of $300 \mathrm{~km} / \mathrm{h}$ and phase of $135^{\circ}$. The performance degrades significantly. The phase has 
distinct influence on the force reduction. At a phase of $150^{\circ}$ and speed of $270 \mathrm{~km} / \mathrm{h}$, the force reduction changes to $65.9 \%$. A phase shift of $135^{\circ}$ can degrade the performance of the DEC.
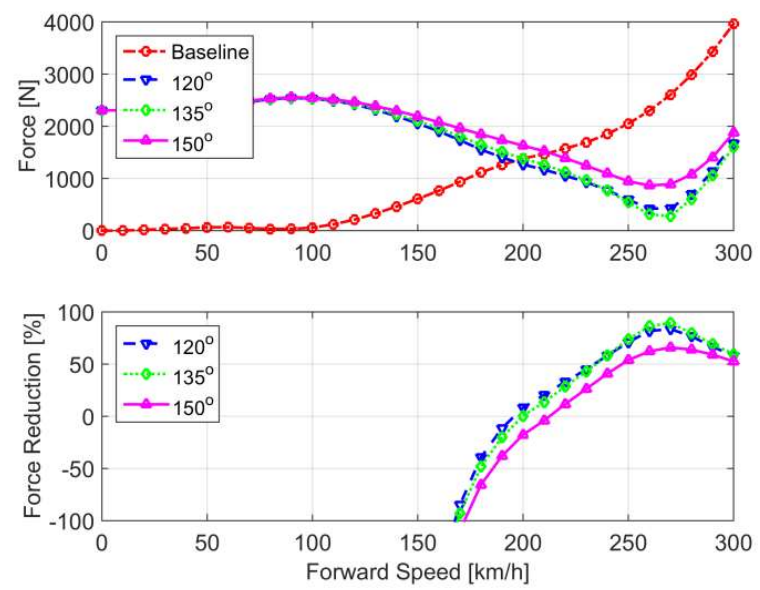

Figure 5: The Vertical force and corresponding reduction for different phase.

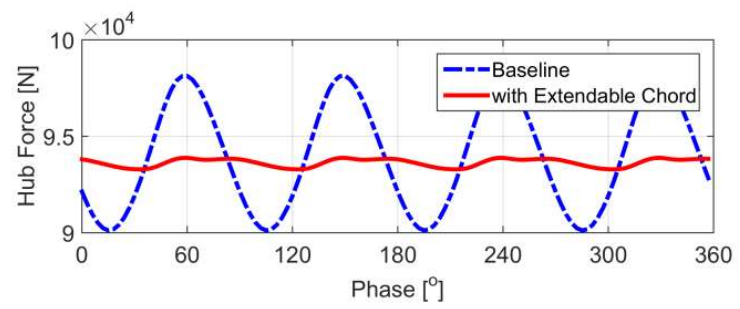

Figure 6: The steady responses of vertical hub force.

From the previous analyses, it is obvious that the DEC is like a force generator, which can generate a harmonic force following the prescribed harmonic input. The resultant of the controlled force with the target harmonic load determines the effect of the DEC. If the DEC generates much larger force than the baseline value, the resultant force can be much large even at hover and low speed flight. It is therefore detrimental to activate the DEC. If the force generated by the DEC just counteracts the baseline, the maximum reduction can be obtained. If it is smaller than the baseline, only part of the force is reduced. It is highly necessary to match the force generated by the DEC with the baseline force following the flight state. 
Figure 6 shows the steady responses, at a speed of $270 \mathrm{~km} / \mathrm{h}$, of the baseline vertical hub force and the force with the DEC (Location 6 and phase of $135^{\circ}$ ). The figure clearly shows the typical characteristics of the 4 peaks for the four bladed rotor. With the DEC, the magnitude of the $4 / \mathrm{rev}$ component decreases by $89.4 \%$. It is expected that, with a suitable combination of the input phase, chord extension and/or chord width, more vertical hub force can be reduced.
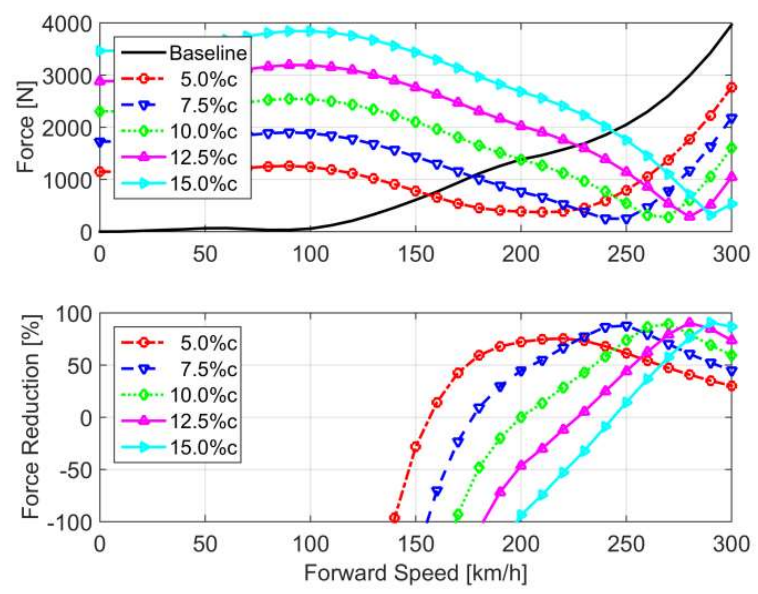

Figure 7: The force reduction for different magnitudes of chord extension.

Figure 7 shows the effect of the magnitude of the 4/rev DEC at Location 6, on the 4/rev vertical hub force and the corresponding force reduction. The phase of the DEC is adjusted to $135^{\circ}$. At hover and low speeds, the force increases. The longer the chord extends, the larger the force becomes. With increasing speed, the force increases slightly, and then decreases. At the critical speed, the maximum force reduction can be obtained. This critical speed increases with the chord extension, which is due to the larger force generated by the longer extension, as shown in Figure 8 . With an extension of $15 \% \mathrm{c}$, the critical speed is $290 \mathrm{~km} / \mathrm{h}$ and the corresponding force reduction of $90.7 \%$ is obtained. If the flight speed is faster than the critical, the reduction decreases. At $300 \mathrm{~km} / \mathrm{h}$, the force reductions for the five cases are $30.1 \%, 44.9 \%, 59.5 \%, 73.7 \%$, and $86.7 \%$, respectively. The performance degrades significantly, and it is necessary to optimize the amplitude of the chord extension following the change of flight state. To achieve best performance at a high speed, a larger chord extension can be adopted. However, larger dynamic chord extension can generate larger torsional excitation moment, which can cause high loads in other directions, and even 
leads to instability. It should be noted that the magnitude of $15 \% \mathrm{c}$ is a large value, and the corresponding maximum chord extension is up to $30 \% \mathrm{c}$. The structural realization may be difficult.
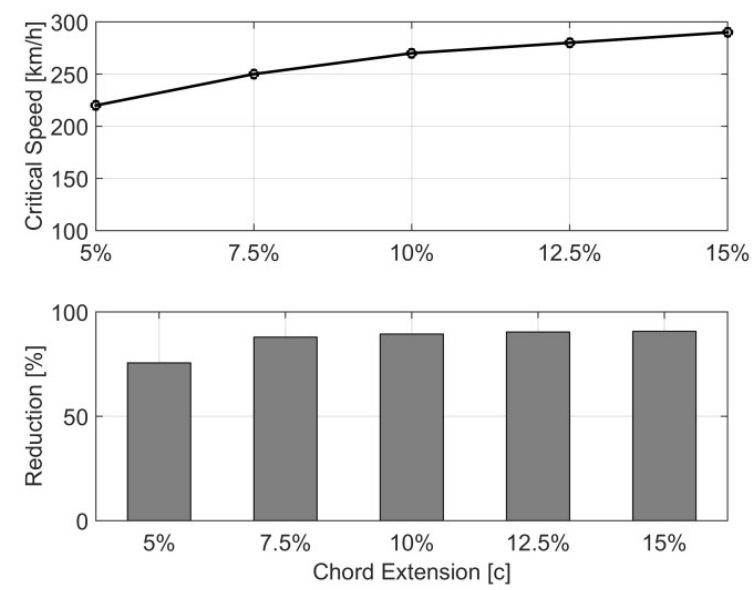

Figure 8: The critical speeds and corresponding force reductions for different chord extension.

Table 2: Effect of DEC location on 4/rev vertical hub force.

\begin{tabular}{cccc}
\hline \hline Location & Maximum Force Reduction & $\begin{array}{c}\text { Critical Speed } \\
(\mathrm{km} / \mathrm{h})\end{array}$ & $\begin{array}{c}\text { Best Phase } \\
(\text { degree })\end{array}$ \\
\hline $30-40 \% \mathrm{R}$ & $94.4 \%$ & 200 & 105 \\
$40-50 \% \mathrm{R}$ & $94.1 \%$ & 250 & 120 \\
$50-60 \% \mathrm{R}$ & $89.4 \%$ & 270 & 135 \\
$60-70 \% \mathrm{R}$ & $92.7 \%$ & 260 & 135 \\
$70-80 \% \mathrm{R}$ & $93.6 \%$ & 220 & 120 \\
$80-90 \% \mathrm{R}$ & $93.7 \%$ & 140 & 90 \\
\hline \hline
\end{tabular}

Table 2 shows the effect of the deployment location of the 4/rev DEC on the maximum 4/rev force reduction, critical speed and corresponding best phase for maximum force reduction. For different locations, the maximum force reduction almost remains constant and is about $90 \%$. The critical speed decreases drastically, when the DEC approaches the blade root or blade tip, since the blade sections at these locations generate less lift than at the middle to outboard part. It is therefore recommended to deploy the DEC at the location from $40 \% \mathrm{R}$ to $70 \% \mathrm{R}$. 


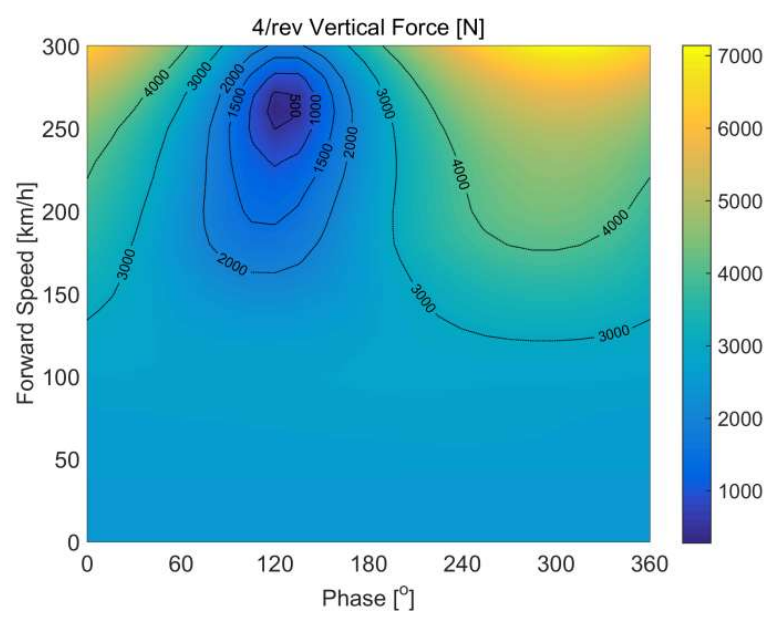

Figure 9: The 4/rev vertical force for different forward speed and input phase $\left(C_{W}=\mathbf{0 . 0 0 8 3}\right)$.
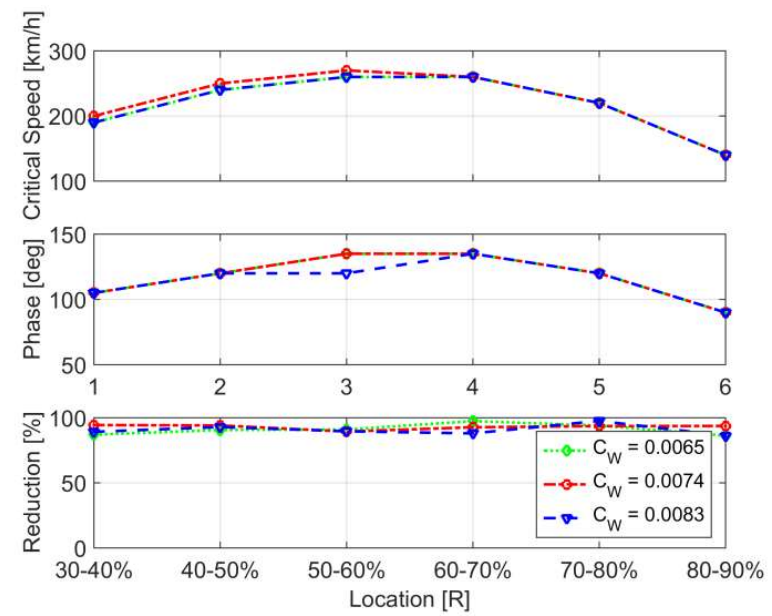

Figure 10: The performance of the DEC for different take-off weights.

Figure 9 shows the 4/rev vertical hub force with the forward speed and the phase of the DEC at a larger weight coefficient of 0.0083 . The DEC is deployed at Location 6 and with $10 \%$ c extension. The effects of the forward speed and the phase on the force reduction are similar as in Figure 4. The critical speed is $260 \mathrm{~km} / \mathrm{h}$ and the corresponding phase is $120^{\circ}$, which are very close to the values at the weight coefficient of 0.0074 . Figure 10 shows the effect of the deployment location on the critical speed, corresponding phase and force reduction for the coefficients of $0.0065,0.0074$ and 0.0083 , respectively. It is obvious that increasing or decreasing the take-off weight has substantially small influence on the performance of the DEC. The change of the take-off weight means 
the change of the lift on the blades, and simultaneously, the lift acting on the dynamic chord increase or decrease proportionally. Naturally, the force reduction has substantially small variation.

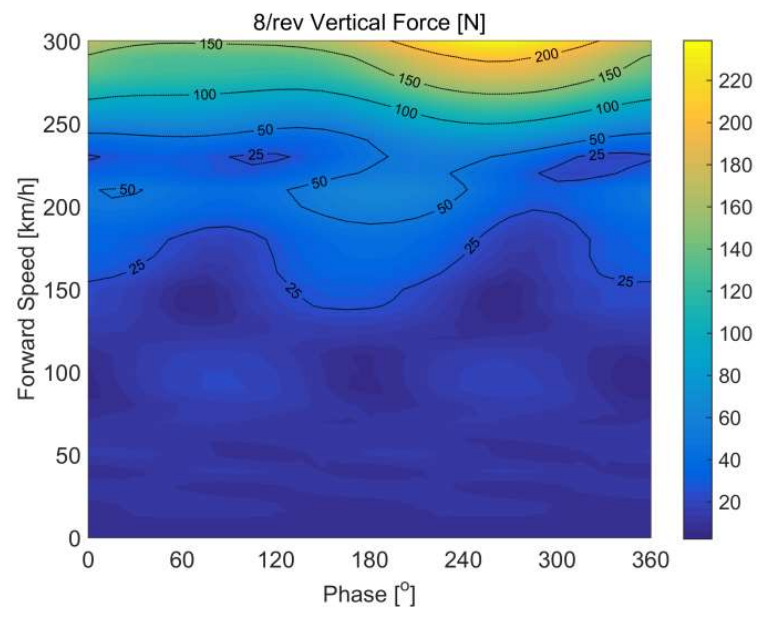

Figure 11: The 8/rev vertical force for different forward speed and input phase.

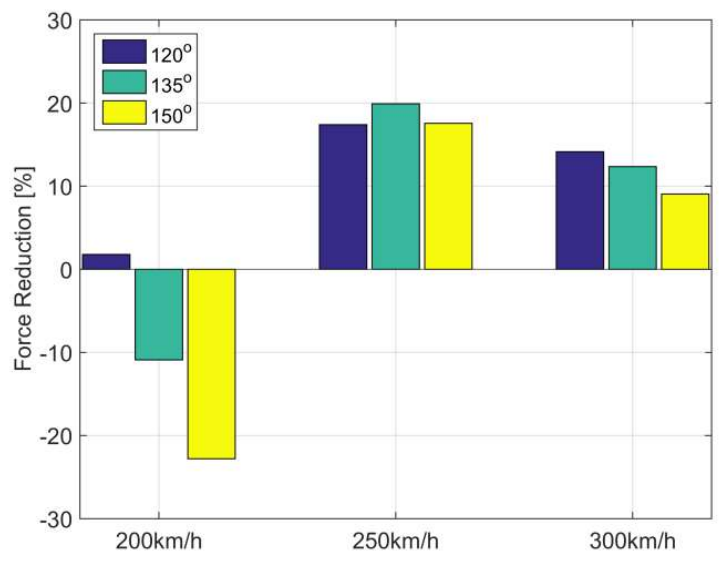

Figure 12: The 8/rev force reduction for different speeds and phases.

Figure 11 shows the effect of the 4/rev DEC on the 8/rev vertical hub force. The DEC is deployed at Location 6 and with $10 \%$ c extension. At hover and low speed flight, the $8 / \mathrm{rev}$ force is small and the effect is relatively small. At high speed flight, the fluctuation of the force with the phase becomes larger, indicating that the 4/rev DEC affects the $8 /$ rev harmonic force. Figure 12 shows the $8 /$ rev force reduction for the three typical phases and speeds. At a 
high speed of $300 \mathrm{~km} / \mathrm{h}$ and phase of $135^{\circ}$, the $4 / \mathrm{rev}$ DEC can reduce the $8 / \mathrm{rev}$ force by $12.4 \%$. The $8 / \mathrm{rev}$ vertical hub force can be reduced simultaneously, but the magnitude is relatively small. Considering the much small magnitude of the $8 / \mathrm{rev}$ force compared with the $4 / \mathrm{rev}$, the effect of the $4 / \mathrm{rev}$ DEC on the $8 /$ rev vertical hub force is negligible.

\section{2/rev and 3/rev Blade Flapwise Root Bending Moment}

The 2/rev and 3/rev blade flapwise root bending moments without the DEC (baseline) are shown in Figure 13. Figure 14 shows the effect of the $2 / \mathrm{rev}$ DEC at Location 6 , on the $2 / \mathrm{rev}$ flapwise root bending moment. The magnitude of the dynamic chord is $10 \% \mathrm{c}$. At a critical speed of $20 \mathrm{~km} / \mathrm{h}$ and phase of $105^{\circ}$, the bending moment is reduced by $74.3 \%$. With increasing the speed, the performance degrades significantly. At a speed of $100 \mathrm{~km} / \mathrm{h}$ and phase of $105^{\circ}$, the moment is reduced by $11.7 \%$. The critical speed is too low, which indicates that the DEC does not effectively control this $2 /$ rev flapwise root bending moment. Table 3 shows the effect of the $2 /$ rev DEC location on the $2 / \mathrm{rev}$ moment reduction. The critical speed is rather small and changes substantially small with the location. The DEC is rather poor for controlling this harmonic flapwise root bending moment. The phase of deployment shows a drastic change, when the DEC approaches the blade tip. In this case, $1 \%$ of the blade area is utilized $(10 \% c \times 10 \% R)$, which only affects a small part of the blade lift. Increasing the width and/or the magnitude of the dynamic chord can reduce the $2 / \mathrm{rev}$ flapwise moment more. But this happens at a speed of $20 \mathrm{~km} / \mathrm{h}$, which is too low. Larger chord width and chord extension may cause severe problems, such as high torsional loads, stability issues, and so on. In addition, the large lower harmonic flapwise loads to be reduced are also an important factor. It can be concluded that the DEC is not suitable for the reduction of the $2 /$ rev flapwise root bending moment. 

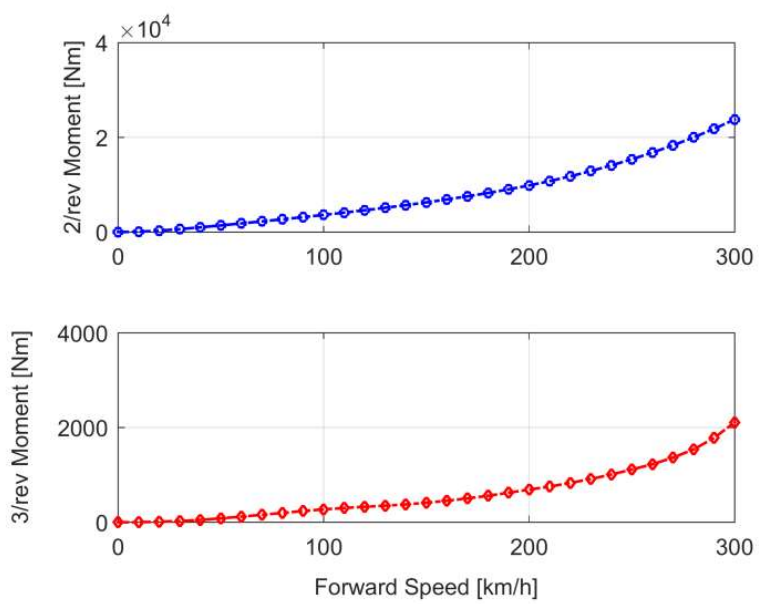

Figure 13: The 2/rev and 3/rev flapwise root bending moments without the DEC.

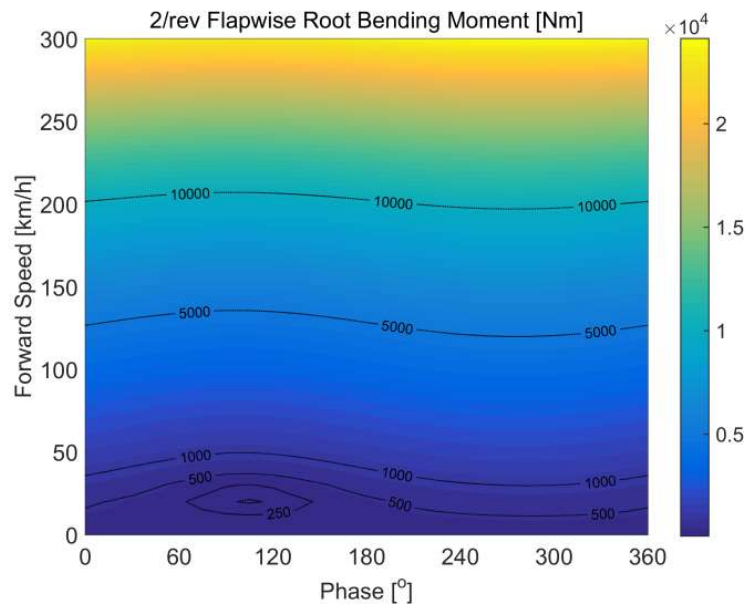

Figure 14: The 2/rev flapwise root bending moment for different forward speed and input phase.

Table 3: Effect of DEC location on 2/rev flapwise root bending moment.

\begin{tabular}{cccc}
\hline \hline Location & Maximum Moment Reduction & $\begin{array}{c}\text { Critical Speed } \\
(\mathrm{km} / \mathrm{h})\end{array}$ & $\begin{array}{c}\text { Best Phase } \\
(\text { degree })\end{array}$ \\
\hline $30-40 \% \mathrm{R}$ & $52.5 \%$ & 20 & 105 \\
$40-50 \% \mathrm{R}$ & $88.4 \%$ & 20 & 105 \\
$50-60 \% \mathrm{R}$ & $74.3 \%$ & 20 & 105 \\
$60-70 \% \mathrm{R}$ & $73.7 \%$ & 20 & 105 \\
$70-80 \% \mathrm{R}$ & $94.2 \%$ & 20 & 90 \\
$80-90 \% \mathrm{R}$ & $61.3 \%$ & 10 & 45 \\
\hline \hline
\end{tabular}




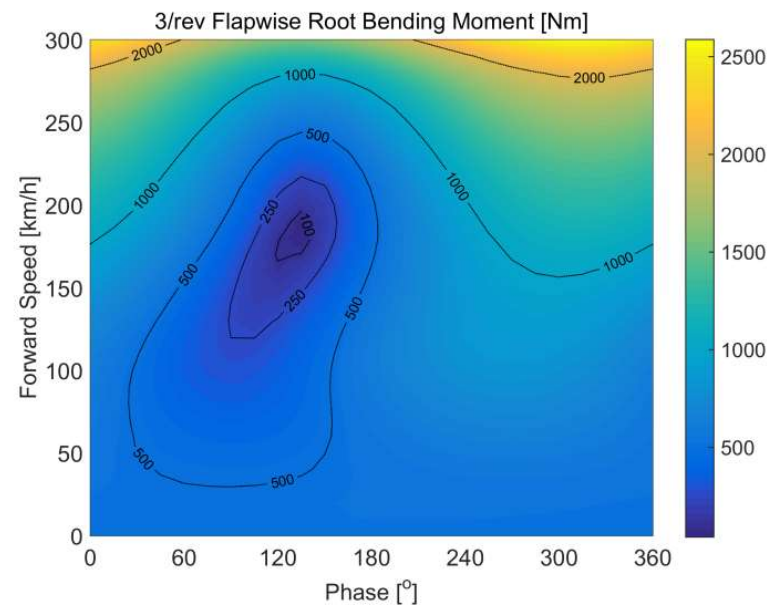

Figure 15: The 3/rev flapwise bending moment for different forward speed and input phase.

Table 4: Effect of DEC location on 3/rev flapwise root bending moment.

\begin{tabular}{cccc}
\hline \hline Location & $\begin{array}{c}\text { Maximum Moment } \\
\text { Reduction }\end{array}$ & $\begin{array}{c}\text { Critical Speed } \\
(\mathrm{km} / \mathrm{h})\end{array}$ & $\begin{array}{c}\text { Best Phase } \\
\text { (degree) }\end{array}$ \\
\hline $30-40 \% \mathrm{R}$ & $95.7 \%$ & 110 & 90 \\
$40-50 \% \mathrm{R}$ & $94.3 \%$ & 160 & 120 \\
$50-60 \% \mathrm{R}$ & $92.6 \%$ & 180 & 135 \\
$60-70 \% \mathrm{R}$ & $88.0 \%$ & 180 & 135 \\
$70-80 \% \mathrm{R}$ & $86.4 \%$ & 140 & 105 \\
$80-90 \% \mathrm{R}$ & $92.3 \%$ & 50 & 45 \\
\hline \hline
\end{tabular}

Figure 15 shows the effect of the 3/rev DEC at Location 6 on the $3 /$ rev blade flapwise root bending moment. The magnitude of the dynamic chord is $10 \% \mathrm{c}$. At a critical speed of $180 \mathrm{~km} / \mathrm{h}$ and phase of $135^{\circ}$, the bending moment is reduced by $92.6 \%$. Increasing the speed, the moment reduction decreases. At a speed of $250 \mathrm{~km} / \mathrm{h}$ and phase of $135^{\circ}$, the moment is reduced by $49.0 \%$. At a high speed, it can reduce part of the baseline. Table 4 shows the effect of the 3/rev DEC location on the 3/rev moment reduction. The critical speed decreases, as the DEC approaches the blade root. Near the blade tip, the critical speed degrades significantly. It is obvious that much less lift is generated at the blade root or tip, which leads to the degradation of the performance of the DEC at these locations. It is not suitable to deploy the DEC near the blade root or tip. 


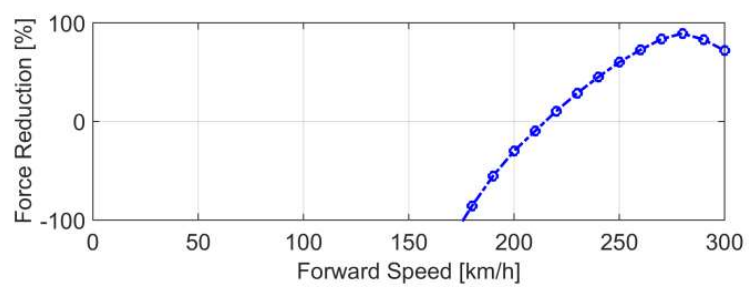

Figure 16: The force reduction for a larger chord width and length extension.

To enhance the ability in reducing the $3 / \mathrm{rev}$ flapwise root bending moment, a suitable means is to increase the width and magnitude of the dynamic chord. Figure 16 shows the effect of the 3/rev DEC at Locations 6 and 7 on the $3 / \mathrm{rev}$ bending moment for $15 \% \mathrm{c}$ extension. The phase of the input is set to $135^{\circ}$. At a critical speed of $280 \mathrm{~km} / \mathrm{h}$, the moment is reduced by $89.2 \%$. At a speed of $300 \mathrm{~km} / \mathrm{h}$, the ratio changes to $72.0 \%$, which is still a large reduction. Increasing the width and magnitude of the DEC is an effective means to generate enough root bending moment in controlling the $3 /$ rev moment. Too large width and magnitude may be not realistic. It is obvious that this concept has great potential in reducing the 3/rev flapwise root bending moment.

\section{4/rev Rotor Rolling and Pitching Moment}

The 4/rev $\left(N_{b} \Omega\right)$ rotor rolling or pitching moment originates from the $3 / \mathrm{rev}\left(\left(N_{b}-1\right) \Omega\right)$ and $5 / \mathrm{rev}\left(\left(N_{b}+1\right) \Omega\right)$ blade flapwise root bending moments. The $3 / \mathrm{rev}$ or $5 / \mathrm{rev}$ DEC is investigated to reduce these $4 / \mathrm{rev}$ moments.

Figure 17 shows the effect of the 3/rev DEC at Location 6 on the 4/rev rotor rolling moment. Again $10 \%$ c extension is used. At a critical speed of $180 \mathrm{~km} / \mathrm{h}$ and phase of $135^{\circ}$, the moment is reduced by $92.3 \%$. When the forward speed is larger than the critical speed, the moment reduction drops. At speeds of $250 \mathrm{~km} / \mathrm{h}$ and $300 \mathrm{~km} / \mathrm{h}$, the values change to $49.7 \%$ and $25.5 \%$. Table 5 shows the effect of the deployment location on the rolling moment reduction. Compared with Table 4, the moment reductions have small difference, but the critical speeds and corresponding phases are almost identical, except near the blade tip. Since the $3 /$ rev blade flapwise bending moment contributes to the $4 / \mathrm{rev}$ rotor rolling moment, the reduction of the $3 / \mathrm{rev}$ bending moment means the simultaneous reduction of the 4/rev rolling moment. Naturally, the disciplines of the moment reductions are identical. It is obvious that it is not suitable to deploy the DEC near the blade root or tip. 


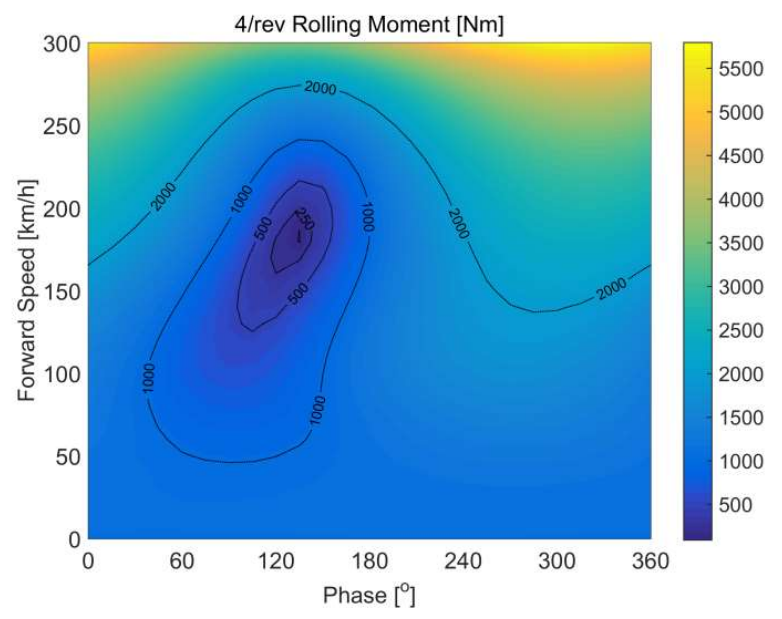

Figure 17: The effect of the 3/rev DEC on the 4/rev roll moment.

Table 5: Effect of 3/rev DEC location on 4/rev rotor rolling moment.

\begin{tabular}{cccc}
\hline \hline Location & $\begin{array}{c}\text { Maximum Moment } \\
\text { Reduction }\end{array}$ & $\begin{array}{c}\text { Critical Speed } \\
(\mathrm{km} / \mathrm{h})\end{array}$ & $\begin{array}{c}\text { Best Phase } \\
(\text { degree })\end{array}$ \\
\hline $30-40 \% \mathrm{R}$ & $99.7 \%$ & 110 & 90 \\
$40-50 \% \mathrm{R}$ & $96.1 \%$ & 160 & 120 \\
$50-60 \% \mathrm{R}$ & $92.3 \%$ & 180 & 135 \\
$60-70 \% \mathrm{R}$ & $91.2 \%$ & 180 & 135 \\
$70-80 \% \mathrm{R}$ & $99.4 \%$ & 130 & 105 \\
$80-90 \% \mathrm{R}$ & $88.0 \%$ & 60 & 120 \\
\hline \hline
\end{tabular}

Table 6 shows the effect of the deployment location on the 4/rev pitching moment. Compared with Tables 4 and 5 , the critical speeds and corresponding phases are almost identical, and the change of the moment reduction is substantially small. Since the 4/rev rotor rolling and pitching moments originate from the 3/rev and 5/rev flapwise root bending moments, the reduction of the 3/rev flapwise root bending moment also means the reductions of the 4/rev rolling and pitching moments. Since the mechanism of the $3 /$ rev flapwise bending moment transferring to the 4/rev rolling moment is identical to the $4 / \mathrm{rev}$ rotor pitching moment, the conclusions drawn from the analysis of the reduction of the 4/rev rolling moment can be applied to the 4/rev pitching moment.

Table 6: Effect of 3/rev DEC location on 4/rev rotor pitching moment.

\begin{tabular}{cccc}
\hline \hline Location & $\begin{array}{c}\text { Maximum Moment } \\
\text { Reduction }\end{array}$ & $\begin{array}{c}\text { Critical Speed } \\
(\mathrm{km} / \mathrm{h})\end{array}$ & $\begin{array}{c}\text { Best Phase } \\
(\text { degree })\end{array}$ \\
\hline $30-40 \% \mathrm{R}$ & $93.8 \%$ & 110 & 90 \\
$40-50 \% \mathrm{R}$ & $93.4 \%$ & 170 & 135
\end{tabular}




\begin{tabular}{lccc}
$50-60 \% \mathrm{R}$ & $92.3 \%$ & 180 & 135 \\
$60-70 \% \mathrm{R}$ & $94.1 \%$ & 170 & 135 \\
$70-80 \% \mathrm{R}$ & $85.8 \%$ & 130 & 105 \\
$80-90 \% \mathrm{R}$ & $87.2 \%$ & 60 & 105 \\
\hline
\end{tabular}

Figure 18 shows the effect of the 5/rev DEC at Location 6 on the 4/rev rotor rolling moment. The magnitude of the dynamic chord is $10 \% \mathrm{c}$. At a critical speed of $120 \mathrm{~km} / \mathrm{h}$ and phase of $60^{\circ}$, the moment is reduced by $90.2 \%$. The critical speed is much smaller than that in Figure 17 for the same deployment location and magnitude of chord extension. It is obvious that the performance achieved by the $5 / \mathrm{rev}$ input is not as good as the $3 / \mathrm{rev}$. When the forward speed is larger than the critical speed, the moment reduction decreases. At a speed of $200 \mathrm{~km} / \mathrm{h}$ or $300 \mathrm{~km} / \mathrm{h}$, the ratios changes to $20.9 \%$ or $3.59 \%$.

Table 7 shows the effect of the deployment location of the 5/rev DEC on the 4/rev rolling moment reduction. The moment reduction decreases significantly near the blade root or blade tip. At the medium to outboard part, better performance can be achieved. Compared with Table 5, it is obvious that the critical speed is generally much smaller than that for the $3 / \mathrm{rev}$ to reduce the $4 / \mathrm{rev}$ rolling moment. It is better to use the $3 / \mathrm{rev}$ DEC to reduce the 4/rev rotor rolling moment.

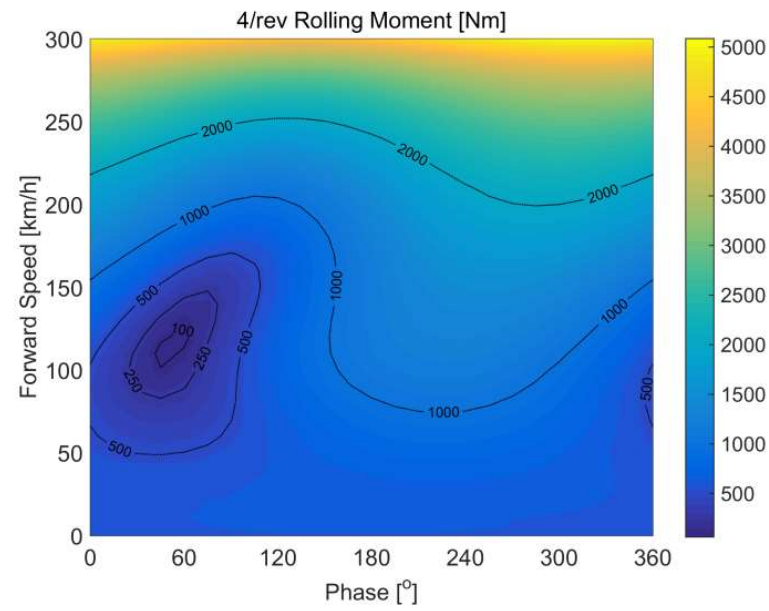

Figure 18: The effect of the 5/rev DEC on the 4/rev rolling moment.

Table 7: Effect of 5/rev DEC location on 4/rev rotor rolling moment.

\begin{tabular}{cccc}
\hline \hline Location & $\begin{array}{c}\text { Maximum Moment } \\
\text { Reduction }\end{array}$ & $\begin{array}{c}\text { Critical Speed } \\
(\mathrm{km} / \mathrm{h})\end{array}$ & $\begin{array}{c}\text { Best Phase } \\
(\text { degree })\end{array}$ \\
\hline
\end{tabular}




\begin{tabular}{lccc}
\hline $30-40 \% \mathrm{R}$ & $91.2 \%$ & 50 & 15 \\
$40-50 \% \mathrm{R}$ & $94.1 \%$ & 80 & 30 \\
$50-60 \% \mathrm{R}$ & $90.2 \%$ & 120 & 60 \\
$60-70 \% \mathrm{R}$ & $93.9 \%$ & 120 & 60 \\
$70-80 \% \mathrm{R}$ & $87.4 \%$ & 90 & 60 \\
$80-90 \% \mathrm{R}$ & $86.5 \%$ & 70 & 120 \\
\hline \hline
\end{tabular}

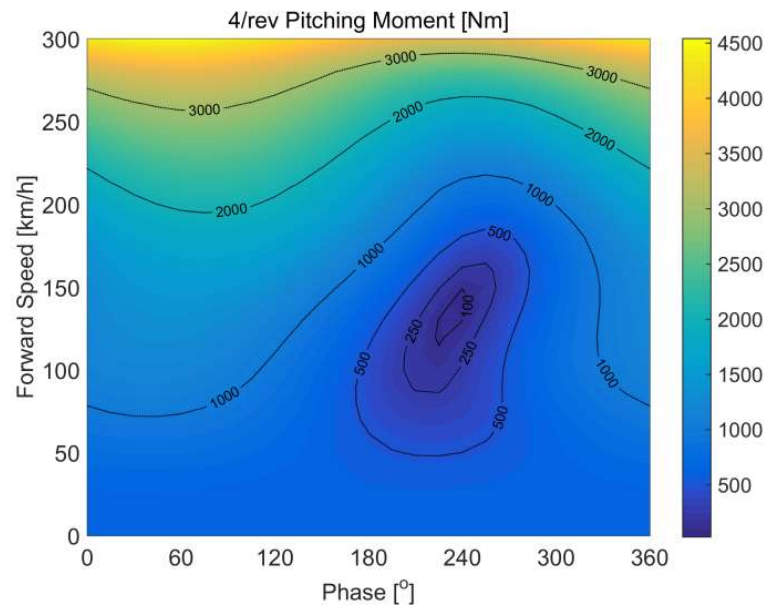

Figure 19: The effect of the $5 /$ rev DEC on the $4 /$ rev pitching moment.

Table 8: Effect of 5/rev DEC location on 4/rev rotor pitching moment.

\begin{tabular}{cccc}
\hline \hline Location & $\begin{array}{c}\text { Maximum Moment } \\
\text { Reduction }\end{array}$ & $\begin{array}{c}\text { Critical Speed } \\
(\mathrm{km} / \mathrm{h})\end{array}$ & $\begin{array}{c}\text { Best Phase } \\
(\text { degree })\end{array}$ \\
\hline $30-40 \% \mathrm{R}$ & $91.0 \%$ & 50 & 195 \\
$40-50 \% \mathrm{R}$ & $95.4 \%$ & 80 & 210 \\
$50-60 \% \mathrm{R}$ & $87.4 \%$ & 120 & 225 \\
$60-70 \% \mathrm{R}$ & $91.2 \%$ & 140 & 240 \\
$70-80 \% \mathrm{R}$ & $96.0 \%$ & 100 & 240 \\
$80-90 \% \mathrm{R}$ & $81.4 \%$ & 60 & 300 \\
\hline \hline
\end{tabular}

Figure 19 show the effect of the 5/rev DEC at Location 6 on the $4 / \mathrm{rev}$ rotor pitching moment. The magnitude of the dynamic chord is $10 \% \mathrm{c}$. At a critical speed of $120 \mathrm{~km} / \mathrm{h}$ and phase of $225^{\circ}$, the moment is reduced by $87.4 \%$. The 5/rev DEC has the equivalent capability in reducing the $4 / \mathrm{rev}$ rotor pitching moment as reducing the $4 / \mathrm{rev}$ rotor rolling moment. 
Table 8 shows the effect of the deployment location of the $5 / \mathrm{rev}$ DEC on the $4 / \mathrm{rev}$ rotor pitching moment. The performance also degrades near the blade root or blade tip. Compared with Table 7, the critical speed changes substantially small, which shows the 5/rev DEC has similar capability in reducing the 4/rev rolling or pitching moment.

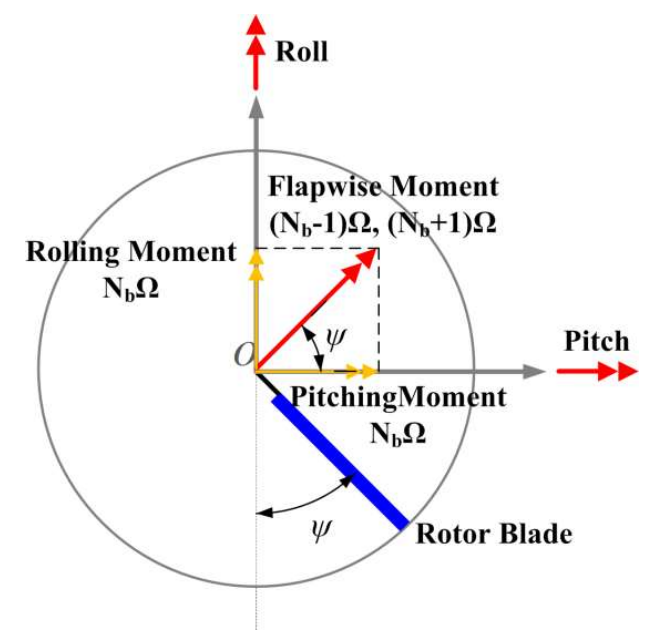

Figure 20: The decomposition of the flapwise root bending moment.

A notable difference between Table 7 and Table 8 is the phase corresponding to the critical speed. Almost all the phase differences are $180^{\circ}$, which is completely different from the phenomenon (almost identical phase) shown in Tables 5 and 6 . As we all know, the $4 /$ rev rotor rolling or pitching moment comes from the $3 /$ rev and $5 /$ rev flapwise root bending moment, as show in Figure 20. Usually the 3/rev harmonic can be much larger than the 5/rev harmonic, usually maybe one order of magnitude higher. It means that the major or most part of the 4/rev moment originates from the 3/rev flapwise root bending moment. Naturally, the reduction of the 3/rev flapwise root bending moment can simultaneously reduce the 4/rev rolling and pitching moments, which is in accordance with the phenomenon shown in Tables 5 and 6 . However, the phenomenon for the $5 / \mathrm{rev}$ DEC is completely different.

The $3 /$ rev flapwise root bending moment can be assumed to be $A_{3} \sin \left(3 \psi+\phi_{3}\right) . A_{3}$ is the amplitude, and $\phi_{3}$ is the phase of the moment. The corresponding rotor rolling and pitching moments from the $3 /$ rev moment are

$$
A_{3} \sin \left(3 \psi+\phi_{3}\right) \sin \psi=-\frac{A_{3}}{2}\left[\cos \left(4 \psi+\phi_{3}\right)-\cos \left(2 \psi+\phi_{3}\right)\right]
$$


and

$$
A_{3} \sin \left(3 \psi+\phi_{3}\right) \cos \psi=\frac{A_{3}}{2}\left[\sin \left(4 \psi+\phi_{3}\right)+\sin \left(2 \psi+\phi_{3}\right)\right]
$$

The $5 / \mathrm{rev}$ root bending moment generated by the $5 / \mathrm{rev}$ DEC is assumed to be $A_{5} \sin \left(5 \psi+\phi_{5}\right)$. Similarly, the corresponding rotor rolling and pitching moments from the 5/rev DEC are

$$
A_{5} \sin \left(5 \psi+\phi_{5}\right) \sin \psi=-\frac{A_{5}}{2}\left[\cos \left(6 \psi+\phi_{5}\right)-\cos \left(4 \psi+\phi_{5}\right)\right]
$$

and

$$
A_{5} \sin \left(5 \psi+\phi_{5}\right) \cos \psi=\frac{A_{5}}{2}\left[\sin \left(6 \psi+\phi_{5}\right)+\sin \left(4 \psi+\phi_{5}\right)\right]
$$

To just counteract the 4/rev rotor rolling moment, the target 4/rev component originating from the $3 /$ rev plus the control component from the $5 /$ rev should equal zero, which is

$$
-\frac{A_{3}}{2} \cos \left(4 \psi+\phi_{3}\right)+\frac{A_{5}}{2} \cos \left(4 \psi+\phi_{5}\right)=0
$$

To make the formula exists, $A_{3}=A_{5}$, and

$$
\cos \left(4 \psi+\phi_{3}\right)-\cos \left(4 \psi+\phi_{5}\right)=0 \Rightarrow-2 \sin \frac{8 \psi+\phi_{3}+\phi_{5}}{2} \sin \frac{\phi_{3}-\phi_{5}}{2}=0
$$

which means,

$$
\sin \frac{\phi_{3}-\phi_{5}}{2}=0
$$

Similarly, to obtain the maximum $4 /$ rev rotor pitching moment reduction, we can derive 


$$
\cos \frac{\phi_{3}-\phi_{5}}{2}=0
$$

It is obvious that it is impossible to make the Equations (17) and (18) come into existence simultaneously. Using the 5/rev DEC to reduce the 4/rev rotor rolling moment may increase the 4/rev rotor pitching moment. For the $4 /$ rev target load originating from the 3/rev flapwise root bending moment with a phase of $\phi_{3}$, the best phase of $\phi_{5}^{r}$ for the $4 / \mathrm{rev}$ rolling moment reduction and the best phase of $\phi_{5}^{p}$ for the $4 / \mathrm{rev}$ pitching moment reduction have the relation

$$
\left|\frac{\phi_{3}-\phi_{5}^{r}}{2}-\frac{\phi_{3}-\phi_{5}^{p}}{2}\right|=\frac{\pi}{2}
$$

which means

$$
\left|\phi_{5}^{r}-\phi_{5}^{p}\right|=\pi
$$

The phase difference corresponding to the maximum moment reduction is $180^{\circ}$ (twice of $90^{\circ}$ ). That is the reason why the phase difference shown in Tables 7 and 8 is $180^{\circ}$.

\section{IV.Conclusion}

Dynamically Extendable Chord (DEC) is utilized here to control the loads of helicopter rotors. A helicopter model is used to explore this concept in controlling the 4/rev vertical rotor hub force, $2 /$ rev and $3 /$ rev blade flapwise root bending moments, and 4/rev rotor rolling and pitching moments, for a four bladed rotor. Parametric analyses are conducted to enhance the potential of chord extension in controlling these harmonic loads. The analyses yielded the following conclusions:

1) For the control of the $4 /$ rev vertical hub force, it is not beneficial to actuate the DEC at hover and low speed flight. At medium to high speed flight, the DEC, with a width of $10 \% \mathrm{R}$ and a chord extension of $10 \% \mathrm{c}$, exhibits great potential in reducing the force. At a higher speed, the performance degrades due to the inability of the DEC to generate enough reacting force. The magnitude of the dynamic chord should be optimized according to the flight state. 
2) For the $4 / \mathrm{rev}$ vertical hub force, the DEC at $40 \%-70 \% \mathrm{R}$ can achieve the best performance. The maximum force reduction can be very close to $90 \%$ or larger.

3) For the $4 /$ rev vertical hub force, the performance of the DEC can be enhanced by increasing the magnitude or width of the dynamic chord.

4) For the $4 /$ rev vertical hub force, the take-off weight has substantially small effect on the performance of the 4/rev DEC, which is due to the simultaneous change of the lift acting on the dynamic chord.

5) The effect of the $4 / \mathrm{rev}$ DEC on the $8 / \mathrm{rev}$ vertical hub force is insignificant due to the much smaller amplitude of the higher harmonic force.

6) The DEC is not suitable for controlling the $2 /$ rev blade flapwise root bending moment.

7) The DEC has great potential in reducing the $3 /$ rev blade flapwise root bending moment. At a speed of $280 \mathrm{~km} / \mathrm{h}$, the $3 / \mathrm{rev}$ moment can be reduced by $89.2 \%$ with a chord width of $20 \% \mathrm{R}$ and a chord extension of $15 \% \mathrm{c}$.

8) The $3 /$ rev DEC can be used to simultaneously reduce the $4 /$ rev rotor rolling and pitching moments. The effectiveness is similar as the control of the $3 /$ rev flapwise root bending moment.

9) The 5/rev DEC can be used to reduce the 4/rev rotor rolling or pitching moment. The effectiveness degrades significantly compared with the $3 / \mathrm{rev}$ dynamic chord. For the control of the $4 / \mathrm{rev}$ target load originating from the 3/rev flapwise root bending moment, the phase difference for the maximum rotor rolling and pitching moment reduction is $180^{\circ}$ for the $5 / \mathrm{rev}$ dynamic chord.

10) For the reduction of the $2 / \mathrm{rev}$ and $3 / \mathrm{rev}$ flapwise root bending moments, the $4 / \mathrm{rev}$ vertical hub force, or the 4/rev rotor rolling and pitching moments, the best deployment place locates at the middle to outboard part, which can generate more lift than near the blade root or tip.

\section{Funding Sources}

This work was supported from the Six Talent Peaks Project in Jiangsu Province (GDZB-013), the National Natural Science Foundation of China (11472129), and the Open Research Foundation of Key Rotor Aerodynamics Laboratory (RAL20180201-1).

\section{References}

[1] Reichert, G., "Helicopter Vibration Control - a Survey,” Vertica, Vol. 5, No. 1, 1981, pp. 1-20. 
[2] Loewy, R. G., "Helicopter Vibrations: A Technological Perspective," Journal of the American Helicopter Society, Vol. 29, No. 4, 1984, pp. 4-30.

[3] Friedmann, P. P., and Millott, T. A., "Vibration Reduction in Rotorcraft Using Active Control: A Comparison of Various Approaches,” Journal of Guidance, Control, and Dynamics, Vol. 18, No. 4, 1995, 664-673.

[4] Friedmann, P. P., "Rotary-Wing Aeroelasticity: Current Status and Future Trends," AIAA Journal, Vol. 42. No. 10, 2004, pp. 1953-1972.

DOI: $10.2514 / 1.9022$

[5] Friedmann, P. P., "On-Blade Control of Rotor Vibration, Noise, and Performance: Just Around the Corner?" Journal of the American Helicopter Society, Vol. 49, No. 4, 2014, pp. 041001.

DOI: 10.4050/JAHS.59.041001

[6] Chattopadhyay, A., Liu, Q., and Gu, H., "Vibration Reduction in Rotor Blades Using Active Composite Box Beam," AIAA Journal, Vol. 38, No. 7, 2000, pp. 1125-1131.

DOI: $10.2514 / 2.1097$

[7] Liu, L., Padthe, A. K., and Friedmann, P. P., “Computational Study of Microflaps with Application to Vibration Reduction in Helicopter Rotors,” AIAA Journal, Vol. 49, No. 7, 2011, pp. 1450-1465.

DOI: $10.2514 / 1 . J 050829$

[8] Han, D., "Flap-wise Loads Reduction of Rotor Blades by Embedded Flap-wise Absorbers," Aeronautical Journal, Vol. 120, No. 1230, 2016, pp.1215-1229.

DOI: $10.1017 /$ aer.2016.53

[9] Léon O., Hayden E., and Gandhi F., "Rotorcraft Operating Envelope Expansion using Extendable Chord Sections," Proceedings of the American Helicopter Society 65th Annual Forum, Grapevine, TX, USA, May 27-29, 2009, pp. 1940-1953.

[10] Khoshlahjeh M., and Gandhi F., "Extendable Chord Rotors for Helicopter Envelope Expansion and Performance Improvement,” Journal of the American Helicopter Society, Vol. 59, No. 1, 2014, pp. 012007101200710 .

DOI: $10.4050 /$ JAHS.59.012007

[11] Kang H., Saberi H. and Gandhi F., "Dynamic Blade Shape for Improved Helicopter Rotor Performance," Journal of the American Helicopter Society, Vol. 59, No. 1, 2010, pp. 032008. 
DOI: $10.4050 /$ JAHS.55.032008

[12] Han, D., Yang, K., and Barakos, G. N., "Extendable Chord for Improved Helicopter Rotor Performance," Aerospace Science and Technology, Vol. 80, 2018, pp. 445-451.

DOI: $10.1016 /$ j.ast.2018.07.031

[13] Han, D., Wang, H.-W., and Gao, Z., “Aeroelastic Analysis of a Shipboard Helicopter Rotor with Ship Motions during Engagement and Disengagement Operations," Aerospace Science and Technology, Vol. 16, No. 1, 2012, pp. $1-9$.

DOI: $10.1016 /$ j.ast.2011.02.001

[14] Han, D., Rahn, C. D., Smith, E. C., "Higher Harmonic Pitch Link Loads Reduction Using Fluidlastic Isolators," Proceedings of the Institute of Mechanical Engineers Part G: Journal of Aerospace Engineering, Vol. 228, No. 3, 2014, pp. 455-469.

DOI: $10.1177 / 0954410013475565$

[15] Peters, D. A., and HaQuang, N., "Dynamic Inflow for Practical Application," Journal of the American Helicopter Society, Vol. 33, No. 4, 1988, pp. 64-68.

[16] Owen, D. R. J., and Hinton, E., Finite Elements in Plasticity: Theory and Practice, Pineridge Press, Swansea, Wales, UK, 1980, pp. 431-436.

[17] Liu, T., Montefort, J., Liou, W., Pantula, S. R., and Shams, Q. A., "Lift Enhancement by Static Extended Trailing Edge, ” Journal of Aircraft, Vol. 44, No. 6, 2007, pp. 1939-1947.

DOI: $10.2514 / 1.31995$

[18] Hilbert, K. B., “A Mathematical Model of the UH-60 Helicopter,” Technical Report NASA-TM-85890, 1984.

[19] Davis, S. J., "Predesign Study for a Modern 4-Bladed Rotor for the RSRA," Technical Report NASA-CR166155, 1981.

[20] Bousman, W. G., “Aerodynamic Characteristics of SC1095 and SC1094 R8 Airfoils," Technical Report NASA/TP-2003-212265, 2003. 